\title{
4B: The natural history of $H$. pylori infection - epidemiological aspects
}

\section{B:01 MARKED DECREASE OF HELICOBACTER PYLORI INFECTION IN ASYMPTOMATIC CHILDREN IN JAPAN}

T. Goto, K. Haruma, T. Kamata, M. Mihara, K. Kiyohira, M. Ito, H. Kawaguchi, M. Yoshihara, K. Sumii, G. Kajiyama. First Dept. of Internal Medicine, Hiroshima University School of Medicine, Hiroshima, Japan

The prevalence of $\mathrm{H}$. pylori infection is significantly higher in the developing than in the developed countries and is closely related to low socioeconomic status. Japan is an exception among the developed countries in that the prevalence of $\mathrm{H}$. pylori infection in people more than 50 years old is approximately $80 \%$. Recent reports demonstrates that its prevalence has declined in the west, especially in children.

The Aim of this study was to investigate the prevalence of $\mathrm{H}$. pylori infection in children and young adults in Japan. Studies in children and young adults are important in determining the epidemiology of $\mathrm{H}$. pylori infection. Methods: The study population consisted of 621 (345 males) asymptomatic Japanese children and young adults between the ages of 0 and 39 years who resided in Hiroshima area. The presence of Hp infection was judged by serum IgG antibody.

Results:

\begin{tabular}{rrr}
\hline Age (yr) & \multicolumn{3}{c}{ Proportion positive } \\
\hline $0-5$ & $1 / 26$ & $(4 \%)$ \\
$6-10$ & $2 / 84$ & $(2 \%)$ \\
$11-15$ & $15 / 106$ & $(14 \%)$ \\
$16-20$ & $23 / 161$ & $(14 \%)$ \\
$21-30$ & $47 / 154$ & $(31 \%)$ \\
$31-40$ & $55 / 90$ & $(61 \%)$ \\
\hline
\end{tabular}

Conclusion: Our results demonstrate that the prevalence of $\mathrm{H}$. pylori infection in Japan has markedly declined in children and young adults. This low prevalence is similar to that in the west and might to be linked to the declining incidence of gastric carcinoma in this country.

\section{B:02 SEROPREVALENCE OF ANTIBODIES TO Cag A AND Vac A} PROTEINS VERSUS GASTRIC CANCER RISK

J.M. Romãozinho, P. Souto, V.L. Rodrigues, J. Baranda, P. Cabral,

C. Sargento, D.S. Freitas. Serv. Gastrenterologia, Hospitais Universidade Coimbra, Coimbra, Portugal

Objectives: To compare the seroprevalence of antibodies to $116 \mathrm{kD}$ (cagA) and $89 \mathrm{kD}$ (vacA) proteins, in young Portuguese populations with Helicobacter pylori (HP) infection, living in areas with different gastric cancer (GC) risk.

Material and Methods: The study focused on 87 young males, between 17 and 19 years old, with comproved HP infection, detected by the presence of specific IgG antibodies in the serum (PiloriTrak ${ }^{\text {TI }}$-ELISA). These teenagers were randomly selected from representatives samples of the population of various Portuguese counties, with different male GC risk Determination of this risk, by the estimation of geographically smoothed Standardized Mortality Ratios (SMR), allowed definition of two groups: low (SMR < 70) and high (SMR > 130) GC risk counties. Antibodies to cagA and vacA proteins were analised with a commercial Western Blot (WB) kit (HelicoBlot2.0 $0^{\text {tw }}$ ). Of the initial 87 serum specimens, 20 were excluded due to Hp negativity by WB. Of the remaining 67,41 belong to GC high risk (HR) counties, whereas 26 were from low risk (LR) counties. Statistic analysis was done by $\chi^{2}$ test.

Results:

\begin{tabular}{lllll}
\hline Antibodies to proteins & \multicolumn{3}{l}{ Prevalence (\%) } & $p^{*}$ \\
\cline { 2 - 4 } & Global & HR* & LR $^{*}$ & \\
\hline cagA & 59.7 & 65.9 & 50 & 0.197 \\
vacA & 55.2 & 61 & 46.2 & 0.234 \\
cagA or vacA & 73.1 & 80.5 & 61.5 & 0.088 \\
cagA and vacA & 41.8 & 46.3 & 34.6 & 0.342 \\
Only cagA & 17.9 & 19.5 & 15.4 & 0.67 \\
Only vacA & 13.4 & 14.6 & 11.5 & 0.72 \\
\hline
\end{tabular}

Conclusions: The seroprevalence of antibodies to cagA and/or vacA was higher in areas of greater GC risk, although this did not reach statistical significance, probably due to the small sample size.

\section{B:03 MOLECULAR FINGERPRINTING OF PRE AND POST TREATMENT ISOLATES OF H. PYLORI USING THE RANDOM AMPLIFIED POLYMORPHIC DNA (RAPD) TECHNIQUE}

T.A. Ghoneim, J.E. Crabtree, A.T. Ghoneim. St. James's University Hospital, Leeds, UK

Twenty three pre and post treatment isolates of $\mathrm{H}$. pylori from gastric biopsies of 11 patients who had suffered ulcer relapse were used in the study. The strains were collected from patients in a large European study to evaluate eradication of $\mathrm{H}$. pylori by Clarithromycin. Of these strains 17 were from patients treated with Omeprazole alone and 6 from 3 patients treated with Clarithromycin + Omeprazole. The strains were chosen in random and represent an independent sample group. They were analysed for strain relatedness using RAPD technique. The heterogenous nature of $H$. pylori was confirmed by RAPD with 17 different DNA profiles generated. $7 / 11$ (64\%) patients harbored a homogenous pre and post treatment isolate, in 3/11 patients the isolates were unrelated and one harbored a possible mixed population. Three pre and post treatment isolates with different RAPD profiles were cultured and 6-10 single colony clones were analysed to establish the homogeneity of the strain. In one patient the presence of more than one RAPD type in the pre treatment sample was demonstrated, with selection of one of the RAPD types post treatment. In conclusion RAPD was found to be a reliable, reproducible and cost effective typing tool for H. pylori. The data suggest that acquisition of new strains is not uncommon and can be an important factor in treatment failures.

\section{B:04 SEROEPIDEMIOLOGY OF H. PYLORI INFECTION AND HEPATITIS A IN A RURAL AREA. EVIDENCE AGAINST A COMMON MODE OF TRANSMISSION}

F. Luzza, M. Imeneo, M. Maletta, G. Paluccio, A. Giancotti ${ }^{1}$, F. Perticone, P. Graziano, A. Foca' ', F. Pallone. Dipartimento Medicina Sperimentale, Universita' di R. Calabria, Catanzaro, Italy; ' Cattedra di Microbiologia, Universita' di $R$. Calabria, Catanzaro, Italy

Background: Recent studies showed that the age-specific prevalence of $H$. pylori infection parallels Hepatitis A (HAV) suggesting similar modes of transmission. Aim: To investigate risk factors for $H$. pylori and HAV and the possiblity that the two infections could be associated. Methods: Between January and September 1995, a random sample of 705 resident subjects who attended the outpatient medical center of the rural county of Ciro' (11.000 inhabitants, Southern Italy) for blood testing were recruited. All subjects completed a questionnaire for general demographic details, height, weight, current and childhood socio-economic circumstances, history of cardiovascular diseases, diabetes, dyspepsia, smoking and alcohol. Serum sample was drawn from each subject and stored at $-20^{\circ} \mathrm{C}$. Blood pressure was measured. All sera were assayed for $H$. pylori specific IgG by an in-house ELISA using a crude $H$. pylori sonicate as antigen (sensitivity and specificity $97 \%$ and $91 \%$ ). In 466 subjects, antibodies to HAV were detected by means of a commercial ELISA kit (Behring, USA). In subsets of subjects, serum fasting cholesterol, triglycerides and glucose were also measured. Data were analysed by multiple logistic regression analysis, Spearman's test, $\kappa$ statistic and expressed also as odds ratio (OR) and $95 \%$ CI. Results: Of the 705 ( $273 \mathrm{M}$; age range 1-87, median 50) subjects, 446 (63\%) were positive for $H$. pylori. Among the $466(163 \mathrm{M}$; age range 1-87, median 49) subjects screened for HAV, $291(62 \%)$ were positive for $H$. pylori and $407(87 \%)$ for HAV. Cross-tabulation of this data showed that $275(59 \%)$ were positive and $43(9 \%)$ negative for both $H$. pylori and HAV, $16(3 \%)$ were positive only for $H$. pylori and $132(28 \%)$ were positive only for HAV (OR $=5.6, \mathrm{CI}$ : $3-10)$. There was an age-specific increase in the prevalence of the two infections and a fair correlation $(r=0.287)$ whereas the association was more weak $(\kappa=0.21)$ or not significant $(\kappa=$ -0.064 ) when assessed in the first two decades. In multivariate analysis, current and childhood socio-economic features were differently associated with $H$. pylori [dyspepsia $(\mathrm{OR}=1.6, \mathrm{CI}: 1.1-2.3)$, occupation $(\mathrm{OR}=0.7$, CI: $0.6-0.9)$ ] and HAV [n. of siblings (OR $=1.3, \mathrm{CI}: 1.05-1.7)$, refrigerator $(\mathrm{OR}=5.6$, CI: 1.3-24)]. Conclusion: The correlation between $H$. pylori and HAV reflects the age-specific high seroprevalence of both infections more than a true association. The fecal-oral transmission of $H$. pylori is unlikely. 


\section{B:05 HELICOBACTER PYLORI INFECTED PATIENTS AND} HOUSEHOLD MEMBERS

C. Martín de Argila, D. Boixeda, R. Cantón, L. de Rafael, N. Mir, J.P. Gisbert, A.L. San Roman. "Ramón y Cajal" Hospital, Madrid, Spain

Reports on the epidemiology of Helicobacter pylori infection are scarce, and the source and spread of this organism are still relevant unanswered questions.

Aim: The aim of this study was to evaluate Helicobacter pylori infection among first- and second- degree relatives and spouses of duodenal ulcer patients with previously demonstrated Helicobacter pylori infection to provide further information on the potential spread of this microorganism mediated by a close personal contact.

Materials and Methods: Sixty-two close personal contacts of 19 patients with duodenal ulcer in whc.n Helicobacter pylori had been cultured from gastric biopsies (18 spouses, 11 siblings, 29 children, and 4 parents) and 272 controls from the same environment and with similar age were studied. Helicobacter pylori-specific IgG antibodies were detected by an enzyme-linked immunosorbent assay (ELISA). Subjects were considered positive when titers were $>10 \mathrm{U} / \mathrm{ml}$.

Results: The antibodies were positive in $81 \%$ of the household contacts of the index patients and in $49 \%$ of the controls $(p<0.001)$. In all families there was at least one member infected. Parents (100\%) and siblings $(100 \%)$ were more likely to be infected than spouses $(78 \%)$ and children (72\%) $(\mathrm{p}<0.001)$.

Conclusions: Clustering of Helicobacter pylori infection within household contacts suggests that a person-to-person spread of these microorganisms or a common source exposure. This fact might account for some therapeutic failures in patients living together with infected household contacts.

\section{B:06 SERO-CONVERSION AND SERO-REVERSION IN IGG ANTIBODIES TO H. PYLORI: AN 11-YEAR FOLLOW-UP OF 2,523 RANDOMLY SELECTED DANES}

S.J. Rosenstock 1,2 , L.P. Andersen ' , O. Bonnevie 1, T. Jørgensen 1,2 ${ }^{1}$ The Copenhagen Hospital Corporation, Denmark; ${ }^{2}$ The Glostrup Population Studies, University of Copenhagen, Denmark

Purpose: To assess the 11-year sero-conversion and sero-reversion rate in IgG antibodies to $H$. pylori in adults. Methods: In 1983, 3,589 Danes aged 30-60 years entered a population-based cohort study. After 11 years, 2,656 participants attended a follow-up examination. A total of 2,523 matching pairs of sera were eligible for this study. IgG antibodies agains $H$. pylori were measured with an in-house ELISA assay. Cut-off points for seronegativity and seropositivity were set at $\leq 100$ ELISA units (Eu) and $\geq 400 \mathrm{Eu}$, respectively. Participants who were IgG seronegative or IgG border-line at study entry and IgG seropositive at follow-up were regarded as sero-converters. All sero-converters had at least a four-fold increase in base-line IgG antibody levels between study entry and followup. Sero-reverters were those who were IgG seropositive at study entry and showed at least a four-fold decrease in IgG antibody levels at followup. Results: Seropositivity for IgG antibodies to $H$. pylori was seen in $24.7 \%$ [23.0-26.4] in 1983 and 24.5\% [22.8-26.2] in 1994. A total of 36 participants sero-converted within the observation period. The cumulated 11-year sero-conversion rate (incidence of $H$. pylori infection) was 18.9 [12.8-25.0] per 1,000 persons at risk. Sero-reversion was seen in $42(\mathrm{~m} / \mathrm{f}$ : 17/25) participants. The cumulated 11 -year sero-reversion rate was 67.4 [47.7-87.1] per 1,000 persons at risk. Conclusions: The incidence of $H$. pylori infection is low in adults. Elimination of $H$. pylori infection seems to outbalance acquisition of the infection in adults in developed parts of the world.

\section{B:07 PREVALENCE AND DETERMINANTS OF H. PYLORI INFECTION IN PRESCHOOL CHILDREN - A POPULATION BASED EPIDEMIOLOGICAL STUDY FROM THE CITY OF ULM, GERMANY}

D. Rothenbacher ${ }^{1}$, G. Bode ${ }^{2}$, G. Berg ${ }^{1}$, R. Gommel ${ }^{1}$, G. Adler ${ }^{2}$, H. Brenner ' ${ }^{\prime}$ Department of Epidemiology, University of Ulm, Germany; ${ }^{2}$ Department of Internal Medicine I, University of Ulm, Germany

Introduction: Helicobacter pylori infection has been recognized as major cause of various gastroduodenal diseases. Infection in early childhood appears to be of particular concern in this respect. There is limited knowledge, however, on the prevalence, determinants and mode of infection. We addressed these issues in a population-based cross-sectional study in Southern Germany.

Methods: Study subjects were all pre-school children in Ulm, a city in the South of Germany, who were screened for school fitness by physicians of the public health service from January until July 1996. Infection status was determined by ${ }^{13} \mathrm{C}$-urease breath test. In addition, the parents of the children were asked to fill out a standardized questionnaire. It comprised information regarding demographic and socioeconomic factors of the family, occurrence of gastrointestinal disorders in the family, as well as housing and living conditions. Furthermore, information on child's hygienic behavior, nutritional behavior and contact to domestic animals were assessed.

Results: Until May 1996, 678 pre-school children were included in the study. The children were aged six $(65.5 \%)$, five $(29.9 \%)$, or seven years $(4.6 \%) .48 \%$ of the subjects were male, $52 \%$ female. The majority were of German nationality $(70.4 \%)$. Overall, 88 children $(13.0 \%)$ were infected with $H$. pylori. There was no variation of prevalence with sex and age. In contrast, nationality and socioeconomic factors were strongly associated with infection status. Furthermore, only childs and children with their own room had a lower prevalence of infection than other children.

Conclusion: Our results indicate an association between childhood living conditions and $H$. pylori infection and point to role of close person to person contact in the transmission of this agent.

\section{B:08 AN EPIDEMIOLOGICAL SURVEY OF CagA SEROPOSITIVITY IN SEVENTEEN WORLDWIDE POPULATIONS}

J.E. Crabtree, P. Webb ${ }^{1}$, D. Newell ${ }^{2}$, A. Covacci ${ }^{3}$, D. Forman and the Eurogast Study Group. St. James's University Hospital \& Leeds

University, UK, ${ }^{1}$ Queensland University, Australia $;{ }^{2}$ Central Veterinary Lab, Weybridge, UK; ${ }^{3}$ IRIS, Siena, Italy

Purpose. Current studies suggest approximately $60-70 \%$ of $\mathrm{H}$. pylor strains have the cagA gene. Molecular analysis has been undertaken on isolates from a limited number of countries and the frequency of cagA worldwide has not been systematically documented. The product of cagA is immunodominant and assay of serum IgG antibodies to CagA is a reliable indicator of infection with strains of the CagA phenotype. In this study we evaluated the prevalence of CagA seropositivity in a random sample selected from the general population of 13 different countries.

Methods. From 2839 subjects (aged 25-34 and 55-64 years) randomly selected from 17 communities in 13 countries worldwide, a group of 1408 had previously been identified as $H$. pylori seropositive by standard ELISA. Sera from these latter subjects were further assayed in a single laboratory for CagA IgG antibodies by ELISA using a purified recombinant fragment of CagA.

Results. Overall 691/1408 (49\%) were CagA seropositive. The \% positivity in different centres ranged from $33 \%$ to $72 \%$. The lowest centres were Iceland (33\%), Greece (37\%), Portugal $(41 \%)$ and the USA $(41 \%)$ The highest levels of CagA seropositivity were Stoke-on-Trent, UK (72\%), Oxford, UK $(69 \%)$ and Belgium (66\%). In this $H$. pylori positive population, the \% CagA positivity was similar in the two age groups $(48 \%$ in 25-34 year olds and 50\% in the 55-64 year olds) and between the sexes (male 49\%, female 50\%).

Conclusions: This study shows that the proportion of $H$. pylori infected individuals who are infected with strains of the CagA phenotype varies throughout the world, with a high prevalence in northern Europe (with the exception of Iceland).

\section{B:09 PREVALENCE OF CagA-POSITIVE H. PYLORI INFECTIONS AMONG HUNGARIAN AND FINNISH DYSPEPTIC PATIENTS}

K. Tamássy ${ }^{1}$, A. Pere ${ }^{2}$, P. Riepponen ${ }^{2}$, K. Juutinen ${ }^{2}$, A. Covacci ${ }^{3}$

R. Rappuoli ${ }^{3}{ }^{1}$ Semmelweis Medical University Teaching Hospital, Budapest, Hungary; ${ }^{2}$ Orion Diagnostica, Espoo, Finland; ${ }^{3}$ IRIS, Siena, Italy

Prevalence of CagA-positive $H$. pylori $(H p)$ infections among 469 Hungarian (HU) and 184 Finnish (FI) dyspeptic patients (DPP) was studied by using an EIA (IgG) with the recombinant CagA protein as antigen. The frequencies of total IgG and IgA antibodies to $H p$ were analysed with Pyloriset EIA-G $G^{\text {TM }}$ (new) and Pyloriset EIA-A ${ }^{\mathrm{TM}}$ (new).

The seroprevalences between ulcer (duodenal, DU and gastrig, GU) and non-ulcer (NUD) patients as well as in different age groups were compared. $H p$ culture and histology were available for all Finnish patients. The results are shown in the tables below.

Conclusions: The prevalence of $H p$ infections among younger DPP is

\begin{tabular}{|c|c|c|c|c|c|c|c|c|}
\hline \multirow[t]{2}{*}{ Age } & \multicolumn{2}{|c|}{$\%$ of DPP } & \multicolumn{2}{|c|}{ CagA pos, $\%$} & \multicolumn{2}{|c|}{ IgG pos, $\%$} & \multicolumn{2}{|c|}{ IgA pos, $\%$} \\
\hline & $\overline{\mathrm{HU}}$ & FI & $\overline{\mathrm{HU}}$ & FI & $\mathrm{HU}$ & $\overline{\text { FI }}$ & $\mathrm{HU}$ & FI \\
\hline $\begin{array}{l}20-29 \\
30-39 \\
40-49 \\
50-79 \\
80-89 \\
\text { Total }\end{array}$ & $\begin{array}{r}7 \\
14 \\
23 \\
51 \\
5 \\
100\end{array}$ & $\begin{array}{r}7 \\
11 \\
14 \\
58 \\
10 \\
100\end{array}$ & $\begin{array}{l}19 \\
60 \\
66 \\
56 \\
45 \\
58\end{array}$ & $\begin{array}{r}8 \\
26 \\
52 \\
59 \\
58 \\
48\end{array}$ & $\begin{array}{l}31 \\
64 \\
73 \\
74 \\
41 \\
68\end{array}$ & $\begin{array}{r}8 \\
37 \\
56 \\
68 \\
79 \\
59\end{array}$ & $\begin{array}{l}13 \\
40 \\
57 \\
60 \\
55 \\
53\end{array}$ & $\begin{array}{r}8 \\
32 \\
44 \\
64 \\
68 \\
54\end{array}$ \\
\hline
\end{tabular}




\begin{tabular}{|c|c|c|c|c|c|c|c|c|}
\hline \multirow[t]{2}{*}{ Diagnosis } & \multicolumn{2}{|c|}{$\%$ of DPP } & \multicolumn{2}{|c|}{ CagA pos, $\%$} & \multicolumn{2}{|c|}{ IgG pos, $\%$} & \multicolumn{2}{|c|}{ IgA pos, $\%$} \\
\hline & $\overline{\mathrm{HU}}$ & FI & $\overline{\mathrm{HU}}$ & FI & $\mathrm{HU}$ & FI & $\overline{\mathrm{HU}}$ & FI \\
\hline $\begin{array}{l}\text { DU } \\
\text { GU } \\
\text { NUD } \\
\text { Total }\end{array}$ & $\begin{array}{r}20 \\
4 \\
76 \\
100 \\
\end{array}$ & $\begin{array}{r}10 \\
9 \\
81 \\
100 \\
\end{array}$ & $\begin{array}{l}79 \\
72 \\
51 \\
58\end{array}$ & $\begin{array}{l}84 \\
59 \\
43 \\
49\end{array}$ & $\begin{array}{l}92 \\
78 \\
62 \\
68\end{array}$ & $\begin{array}{r}100 \\
77 \\
53 \\
60\end{array}$ & $\begin{array}{l}67 \\
78 \\
49 \\
53\end{array}$ & $\begin{array}{l}95 \\
71 \\
43 \\
51\end{array}$ \\
\hline
\end{tabular}

markedly higher in Hungary than in Finland. The frequency of CagA positives among $\mathrm{Hp}$-infected dyspeptic patients is similar in both populations. The difference between Hungary and Finland in the relative frequency of duodenal ulcer and gastric ulcer, and that of CagA and IgA positives in these diagnostic groups is noteworthy.

\section{B:10 STRIKING DIFFERENCE IN IMMUNOBLOTTING RESULTS BETWEEN MAGHREBIS AND EUROPEAN HP POSITIVE ULCER PATIENTS}

C. Jonas, M. N'Kuize, A.M. Van Loey, I. Laurent, M. Dineur, E. De Koster, M. Deltenre. CH César de Paepe and CHU Brugmann ULB-VUB Brussels Belgium

Background: Maghrebis have a higher acquisition rate of HP during childhood than Belgian natives of the same generation. Adult Maghrebis are more susceptible to develop duodenal ulcer than Belgians, but less intestinal metaplasia of gastric mucosa. Goal: to detect, through immunoblotting, a possible difference between the two populations, either in the contaminating strain or the immune response. Method: the sera of $78 \mathrm{HP}$ positive patients (Sydney system and positive IgG serology-Sorin) with active PUD were analyzed by western blot kit (Helico Blot Genelabs Diagnostics): 40 patients from Morocco (M/F: 5.0 mean age $40 \mathrm{y} \pm 11.2$ ) and 38 from Belgium (M/F: 1.9 mean age 52.6 $\pm 13.4 \mathrm{y}$ ). Mean basal gastrinemia was respectively $78.4 \mathrm{pg} / \mathrm{ml} \pm 26.2$ and $82.0 \mathrm{pg} / \mathrm{ml} \pm 35.9$ and the mean titer of IgG antibodies $51.1 \mathrm{AU} / \mathrm{ml} \pm 18.2$ and $48.5 \mathrm{AU} \pm 24.6$ (NS). Results:

\begin{tabular}{llllll}
\hline $\begin{array}{l}\text { Antibody } \\
\text { Hp Antigen }\end{array}$ & $\begin{array}{l}\text { Maghrebis } \\
\text { n positive }\end{array}$ & \multicolumn{3}{c}{$\begin{array}{l}\text { Belgians } \\
\text { n positive }\end{array}$} & $\mathrm{p}$ \\
\hline $116 \mathrm{kDa}$ & $40 / 40$ & $100 \%$ & $30 / 38$ & $80 \%$ & $<0.005$ \\
$89 \mathrm{kDa}$ & $28 / 39^{*}$ & $72 \%$ & $13 / 36^{*}$ & $36 \%$ & $<0.002$ \\
$35 \mathrm{kDa}$ & $32 / 40$ & $80 \%$ & $18 / 40$ & $26 \%$ & $<0.002$ \\
\hline
\end{tabular}

*3 non-interpretable tests.

Despite similar immune reaction in IgG antibodies and similar basal hypergastrinemia, adult ulcer patients from Mahgreb show a significantly greater immune reactivity against $116 \mathrm{KDa}, 89 \mathrm{KDa}$ and $35 \mathrm{KDa} \mathrm{HP}$ antigens. Maghrebis might have been contaminated by strains with a different virulence, or may display a different immune response.

\section{B:11 COUNTRY-SPECIFIC CONSTANCY BY AGE IN CagA ${ }^{+}$ PROPORTION OF H. PYLORI INFECTIONS}

G.I. Pérez-Pérez ${ }^{1}$, N. Bhat ${ }^{1}$, J. Gaensbauer ${ }^{1}$, D. Taylor ${ }^{2}$, E.J. Kuipers ${ }^{1}$, L. Zhang ${ }^{3}$, W.-C. You ${ }^{4}$, M.J. Blaser ${ }^{1}{ }^{1}$ Vanderbilt University and Veterans Affairs Medical Center, Nashville, TN; ${ }^{2}$ NAMRID, Lima Peru;

${ }^{3}$ Beijing Institute for Cancer Research, China $;{ }^{4}$ National Cancer Institute, Bethesda, MD

Chronic infection with $H$. pylori is now firmly linked with the development of adenocarcinoma of the stomach. $H$. pylori strains may be either cagA $^{+}$(about $60 \%$ in the U.S.) or cagA, ${ }^{-}$and in studies of single populations, infection with cagA ${ }^{+}$strains was associated with increased risk for developing atrophic gastritis and gastric adenocarcinoma. We sought to determine the extent to which CagA seroprevalence varied in the world and whether differences in prevalence were associated with variation in gastric cancer rates. We used an enzyme-linked immunosorbent assay (ELISA) to detect serum IgG to CagA as described (Cancer Research 1995; 55: 2111), for screening sera from 385 asymptomatic adults between 20 and 65 years old from Manitoba, Canada $(n=105)$; Lima, Peru $(n=90)$; Shandong, China $(n=66)$; Soongnern, Thailand $(n=66)$; and the Netherlands $(n=$ 66). In total, the CagA seroprevalence in Peru and Thailand $(82.2 \%$ and $78.8 \%$, respectively) were each substantially higher than for the Chinese (37.9\%), Dutch (39\%), and Canadian (41.9\%) subjects. Within each population, gender-based differences were observed; however, strikingly, rates were relatively constant across age groups. Comparison of reported gastric cancer rates for the 5 studied populations with $H$. pylori seroprevalence or determined $\mathrm{CagA} \mathrm{A}^{+}$prevalence rates showed an association with the former but not with the latter. Considering that most $H$. pylori infection is acquired in childhood, the data we report suggests that the relative proportion of cagA $^{+}$infections among all $H$. pylori infections has changed little in recent years in these areas.

\section{B:12 AN ACCURATE MEASURE FOR THE ASSOCIATION BETWEEN HELICOBACTER PYLORI AND ULCER DISEASE. RESULTS OF THE SEPD CASE-CONTROL STUDY}

Spanish Society of Digestive Diseases (SEPD), Juan Arenas, Fernando Carballo. Unidad de Investigación, Hospital General Universitario, c/ Donantes de Sangre s/n 19002 Guadalajara

The epidemiological evidence of the association between Helicobacter pylori $(H p)$ and ulcer disease is mainly founded in data about a high prevalence of infection among ulcer patients and the lack of ulcer relapses following bacterial eradication. However, previously has not been reported any accurate measure in its degree of association. Aim: To obtain a measure (OR) on the association between $H p$ and ulcer disease based in a sufficiently powerful case-control study. Patients and Methods: The study was promoted by the Spanish Society of Digestive Diseases (SEPD) in collaboration with Schering-Plough. 5,025 patients were included $(2,275$ controls and 2,739 ulcers) from all Spanish regions. An endoscopy, a colorimetric test for the serological diagnosis of $H p$ infection (Helisal) and a brief questionnaire, including data about social status and NSAID use, were performed in each case and control. The results are expressed as prevalence of infection between cases and controls, crude OR and its adjusted measure obtained by unconditioned logistic regression models. Results: The prevalence of Hp positive serology was $44.6 \%$ among controls ( $\mathrm{Cl}_{95 \%}$ 42.56; 46.69) and $79.5 \%$ among ulcers $\left(\mathrm{Cl}_{95 \%} 77.92 ; 80.98\right)$. This prevalence was higher in the duodenal ulcer $(81.6 \%)$ than in the gastric (71.9\%) or pyloric $(74.3 \%)$. The table summarizes the results for the measure of the association showing the crude and logistic OR. In the logistic models other variables were included such as gender, age, NSAID use, educational level and geographical location.

\begin{tabular}{lllll}
\hline Ulcer & Crude OR & CI $_{95 \%}$ & Log OR & CI $_{95 \%}$ \\
\hline All cases & 4.81 & $4.23 ; 5.46$ & 4.80 & $4.15 ; 5.55$ \\
Gastric & 3.17 & $2.54 ; 3.96$ & 3.14 & $2.42 ; 4.07$ \\
Pyloric & 3.58 & $2.37 ; 5.43$ & 3.51 & $2.35 ; 5.25$ \\
Duodenal & 5.51 & $4.77 ; 6.35$ & 5.50 & $4.67 ; 6.48$ \\
\hline
\end{tabular}

Conclusions: The results confirm a very strong association between the $H p$ serological status and ulcer disease, specially in its duodenal form, providing for a first time a very accurate measure of its degree of association.

\section{B:13 SEROPREVALENCE TO HELICOBACTER PYLORI INFECTION IN MEXICO}

J. Torres ${ }^{1}$, Y. Leal-Herrera ${ }^{1}$, M. Camorlinga-Ponce ${ }^{1}$,

C. Jiménez-Ramírez ', A. Gómez ', O. Muñoz ' , R. Tapia-Conyer ${ }^{2}$,

G. Fernández-Quintanilla ${ }^{2}$, G. Pérez-Pérez ${ }^{3}$. ${ }^{1}$ Instituto Mexicano del

Seguro Social, DF, México; ${ }^{2}$ Secretaría de Salud, DF, México;

${ }^{3}$ Medicine-Vanderbilt University, Nashville, USA

In the last years it has been demonstrated the importance of $H$. pylori in gastritis, peptic ulcer disease and gastric cancer. However, few national survey studies have been reported; and there is no epidemiological information on $H$. pylori infection in México. Serum IgG antibodies against sonicated whole cell antigens were measured by ELISA. Antigen was a pool of three $H$. pylori strains isolated in México; and the test was validated in Mexican patients. Serum samples were obtained during a National health survey from March 1987 to June 1988, using a master sampling frame based on General Population Census data. A total of 11,626 serum samples were studied, representing individuals 1 to 90 years old from all States of the country. We found 7,720 seropositive samples for a $66.4 \%$ seroprevalence of infection. The annual acquisition rate was higher during the first decade of life $(4.15 \%)$ and decreased during the second $(1.53 \%)$ and third $(0.87 \%)$ decade. Low socio-economic level and high density of living were directly associated with higher seroprevalence during the first three decades of life; but this correlation was lost after the age of 30 years. No clear correlation with type of population was found, although seroprevalence tend to be lower in urban areas (cities with $>2,500$ inhabitants) as compared with metropolitan (the four biggest cities in the country) and rural $(<2,500$ inhabitants) areas in all ages. $H$. pylori infection is highly prevalent in México and acquisition occurs early in life similar to other developing countries.

\section{B:14 A FIVE-YEARS FOLLOW-UP IN BLOOD DONORS SERONEGATIVE FOR HELICOBACTER PYLORI (HP)}

M. Menegatti, F. Landi, D. Palli, B. Massardi, C. Ricci, J. Holton, A. Alì, S. Farinelli, F. Mucci, C. Saieva, M. Miglioli, D. Vaira. Ist Medical Clinic, Bologna, Center for Oncology Study and Prevention, Florence, Italy; Microbiology Dept, University College London Hospital, London, UK

Background: in developed countries, the infection rate for HP, evaluated as seroconversion from negative to positive, is estimated between 0.5 and $1.5 \%$ /year approximately. 
Aim: to assess HP infection rate in Italian blood donors over a period of 5 years.

Methods: 588/1010 (M/F: 556/454, age: range 18-65, mean 44 years) (58\%) donors screened as seronegative in 1990 were invited for a new IgG assessment in 1995-96. Serology was by an "in house" ELISA assay previously validated with sensitivity and specificity over $90 \%$. Results are expressed as Adsorbance Index (AI) where $\mathrm{AI}>0.30$ is considered positive. ELISA assay on original serum sample, stored at $-20^{\circ} \mathrm{C}$, was repeated for each subjects.

Results: Up today 315 donors were re-evaluated (M/F: 187/128, age: range 23-65, mean 42 years). Repeat assessment of original serum showed: $19 / 315(6 \%)$ positive and 296/315 (94\%) confirmed as seronegative. A total of 5/296 were found to be seropositive at the follow-up sample. The table shows the results at repeated assay in 1996 compared to previous results ( \pm ve $=$ positive/negative)

\begin{tabular}{lll}
\hline & +ve & -ve \\
\hline$+v e(n=19)$ & 19 & $-\overline{1}$ \\
$-v e(n=296)$ & 5 & 291 \\
\hline
\end{tabular}

Assuming the seroconversion at mid point of considered period, for the 296 seronegative donors have been considered 1522 years-person of follow-up, the mean follow-up was 5.2 years (range 4.9-5.8 years) with a seroconversion rate of $0.33 \%$ year $(95 \% \mathrm{CI}=0.1-0.8)$.

Conclusion: we confirm an extremely low HP seroconversion rate in blood donors in a developed country.

\section{B:15 A MULTICENTER STUDY ON HELICOBACTER PYLORI (HP) IN 3281 ITALIAN DYSPEPTICS: FINAL REPORT}

D. Vaira and the Italian Helicobacter pylori Study Group. 1st Medical Clinic, S. Orsola Hospital, Nuove Patologie via Massarenti, 9 Bologna 40138, Italy

Aim: to assess the prevalence of HP by serology and histology according to endoscopic findings and its association with sociodemographic determinants in patients referred for endoscopy through Italy.

Methods: in 93 Endoscopy Units through Italy 30 to 40 patients referred for the first time to endoscopy were enrolled. During endoscopy antral biopsies for urease test, histology (Haematoxylin \& Eosin) and HP determination (Giemsa) were taken; a $10 \mathrm{ml}$ blood sample was analysed for IgG by a commercially available kit (Helori-Test, Eurospital Trieste, Italy).

Results: 3281 patients endoscoped: $\mathrm{M} / \mathrm{F}=1718 / 1563$, age range $18-90$ yrs, mean 48.8 yrs.

Table 1. Multivariate analysis of association of HP with sociodemographic determinants

\begin{tabular}{llll}
\hline Variable & Level & $\mathrm{p}$ & $\mathrm{OR}$ \\
\hline Residence & South/North of Italy & 0.0001 & 1.55 \\
Sex & Female/Male & 0.0160 & 0.81 \\
Education & High/low/medium & 0.0001 & 0.64 \\
Age & log (year) & 0.0001 & 4.67 \\
\hline
\end{tabular}

Age $\log$ (year)

Table 2. HP prevalence (\%) by serology (Helori) and histology (Giemsa)/urease test in the different endoscopic findings

\begin{tabular}{lllllll}
\hline & $\mathrm{N}$ & G/D & GU & DU & GC & O \\
\hline Helorit & 59 & 71 & 82 & 90 & 75 & 63 \\
Giemsa/urease+ & 57 & 65 & 82 & 90 & 64 & 57 \\
\hline
\end{tabular}

$\mathrm{N}=$ normal, $\mathrm{G} / \mathrm{D}=$ gastritis/duodenitis, $\mathrm{GU} / \mathrm{DU}=$ gastric/duodenal ulcer, $\mathrm{GC}=$ gastric cancer, $\mathrm{O}=$ other

Conclusions: Our data show: 1. a strong association of HP with demographic determinants; 2 . a sensitivity and specificity of $92 \%$ and $78 \%$ respectively (histology by referral pathologist as gold standard).

\section{B:16 INFECTION OF PARTNERS: IS IT A RISK FACTOR FOR HELICOBACTER PYLORI REINFECTION?}

J.P. Gisbert, D. Boixeda, C. Martín de Argila, R. Bárcena, T. Pérez, L. Moreno, A. García Plaza. "Ramón y Cajal" Hospital, Madrid, Spain

Purpose: At present it is unknown whether $H$. pylori status of spouses plays a role in reinfection after successful eradication. Our purpose was to study the incidence of reinfection in a one-year follow-up period after eradication of $H$. pylori and to describe the prevalence of infection in spouses of these patients.

Methods: Thirty-three patients (mean age: $49 \pm 12$ yrs, $79 \%$ males) with duodenal ulcer in whom $H$. pylori had been successfully eradicated (with bismuth triple therapy, or omeprazol plus one or two antibiotics) were prospectively studied. Endoscopy with biopsies (H\&E), and $\mathrm{C}^{13}$-urea breath test were performed 1 month after completing therapy. Eradication was defined as the absence of $H$. pylori by both methods. $\mathrm{C}^{13}$-urea breath was repeated at 6 and 12 months. At the 1-year follow-up visit, a breath test was also performed to respective partners.

Results: At the 6-month control, all patients were $H$. pylori-negative. At 1-year, two patients become reinfected ( 52 and 63 years old, respectively), which represents an incidence of reinfection of 6\% (CI95\%: 1.7-20\%). The mean age of spouses was $49 \pm 13 \mathrm{yrs}$, and their prevalence of $H$. pylori infection was $82 \%(n=27)$ (higher than the corresponding prevalence in similar age-population), with a mean $\delta^{13} \mathrm{CO}_{2}$ level of $35 \pm 27$. The mean time of living together was $24 \pm 1$ yrs. None had a previous history of peptic ulcer, and only two (6\%) complained from ulcer-like symptoms. Reinfection occurred in $7.4 \%(2.1-23 \%)$ of patients when the spouse was infected, and in $0 \%$ if the spouse was $H$. pylori-negative (a non-significant difference; the power of the study was only $10 \%$ ). Thus, even if the spouse is infected, $92.6 \%$ of patients persist uninfected one year after eradication.

Conclusion: These preliminary results suggest that further studies are needed to assess a possible role of spouses infection in the reinfection rate after $H$. pylori eradication. It seems that reinfection is uncommon even if partners are $\boldsymbol{H}$. pylorit. However, if a role is demonstrated, therapy against the organism could be recommended also in infected spouses.

\section{B:17 FREQUENCY OF INFECTION BY H. PYLORI IN THE 4TH AND 15TH DISTRICT OF BUDAPEST WITH REGARD TO AGE AND TOPOGRAPHY (AN EPIDEMIOLOGICAL ANALYSIS SURVEYING 2151 PATIENTS)}

A. Takáts ${ }^{1}$, Z. Óvári ${ }^{1}$, A. Szentmihályi ${ }^{2}$, G. Gerổ ${ }^{1}$, J. Penyige ${ }^{1}$,

B. Boga ${ }^{1}$, Gy. Molnár ${ }^{2}$, I. Kovalik ${ }^{3} .{ }^{1}$ Ujpesti Hospital, Budapest,

Hungary; ${ }^{2}$ National Health Institute, Budapest, Hungary; ${ }^{3}$ Semmelweis University of Med., Budapest, Hungary

In our gastroenterological department we have investigated the presence of H. pylori [HP] is specimen from gastric mucosa since 1988. The method for the detection of HP was histological examination (by staining sec. Warthin-Starry) and cultivation. Between 1988.05-1996.04 we examined 2151 patients [PTS] (average age 48.99 years). The distribution of infection by HP in the PTS is presented in the next table:

\begin{tabular}{lccccccccr}
\hline Age (years) & $0-20$ & $21-30$ & $31-40$ & $41-50$ & $51-60$ & $61-70$ & $71-80$ & $81-99$ & Total \\
\hline Male HP+ & 3 & 48 & 93 & 156 & 134 & 67 & 35 & 12 & 548 \\
Male HP- & 16 & 35 & 63 & 104 & 82 & 62 & 32 & 8 & 402 \\
Female HP+ & 15 & 42 & 127 & 186 & 107 & 104 & 60 & 22 & 663 \\
Female HP- & 36 & 61 & 102 & 104 & 80 & 65 & 60 & 30 & 538 \\
HP+ & 18 & 90 & 220 & 342 & 241 & 171 & 95 & 34 & 1211 \\
HP- & 52 & 96 & 165 & 208 & 162 & 127 & 92 & 38 & 940 \\
PTS total & 70 & 186 & 385 & 550 & 403 & 298 & 187 & 72 & 2151 \\
AHP+ \% & 25.7 & 48.4 & 57.1 & 62.2 & 59.8 & 57.4 & 50.8 & 47.9 & 56.3 \\
\hline
\end{tabular}

We have made a geographical map of the territorial frequency of HP infections in North-Pest, marking the HP negative and HP positive cases in the map of the 4th and 15th districts according to PTS addresses. It can be observed that the rate of HP infection in the PTS examined have varied depending on the living place: it has been much higher in the regions of housing estates and the regions full of temporary flats with low comfort than in the garden-city. We have made culture and PCR examinations from drinking water samples in the more infected regions as well as in the less infected ones, to determine HP occurrence. We haven't succeeded in demonstrating HP in these samples.

Conclusions: Our data demonstrate that HP infection increases after age 20 with culmination in age-group 41-50 and we can support the opinion that the inadequate social and hygienic circumstances contribute to the infection by HP.

\section{B:18 DIFFERENT PREVALENCE OF H. PYLORI INFECTION IN NEWBORNS, CHILDREN AND YOUNG ADULTS LIVING IN THE SAME GEOGRAPHIC REGION DUE TO DIFFERENT ETHNIC ORIGN}

W.E. Doppl, M. Tuncay, Y. Bilgin, M. Oezcueremez, H.U. Klör, K. Federlin. III. Dept. of Internal Medicine, Justus Liebig-University of Giessen, Germany

In a small pilot study on young Turks and Germans growing up in Germany we found a different rate of infection of $\mathrm{H}$. pylori among this two ethnic groups. (Amer J Gastroenterol 1994, 89: 1303). In the present study we tried to validate and explain this finding on a larger population. Methods: H. pylori IgG-antibodies levels were estimated by an ELISA (Elias Inc., Freiburg, Germany) in 794 German and 449 Turkish newborns, infants, children and in young adults living in the Giessen area in Germany. The samples were recruited from nongastroenterologic pediatric and internal patients. Levels $\geq 10 \mathrm{U} / \mathrm{L}$ were defined as positive. The results are shown in Tables 1 and 2 .

There was a significant higher rate of infection with H. pylori in Turks as 
Table 1. H. pylori prevalence, Germans

\begin{tabular}{lllllll}
\hline \multicolumn{7}{l}{ Age (years) } \\
\cline { 2 - 7 } & $0-0.5$ & $0.6-5$ & $6-10$ & $11-15$ & $16-20$ & $20-30$ \\
\hline Positive (n) & $20 / 145$ & $24 / 227$ & $15 / 157$ & $24 / 124$ & $14 / 53$ & $29 / 88$ \\
Positive (\%) & 13.8 & 10.6 & 9.6 & 19.4 & 26.4 & 32.9 \\
\hline
\end{tabular}

Table 2. H. pylori prevalence, Turks

\begin{tabular}{lllllll}
\hline & Age (years) & & & & \\
\cline { 2 - 7 } & $0-0.5$ & $0.6-5$ & $6-10$ & $11-15$ & $16-20$ & $20-30$ \\
\hline Positive (n) & $13 / 28$ & $16 / 102$ & $30 / 84$ & $53 / 95$ & $26 / 43$ & $64 / 97$ \\
Positive (\%) & 46.4 & 15.7 & 35.7 & 57.0 & 60.5 & 66.0 \\
\hline
\end{tabular}

compared to Germans in all age groups. The overall prevalence of $\mathrm{H}$. pylori positivity was $45.0 \%$ in Turks and $15.9 \%$ in Germans. There was no difference in gender distribution (57\% males in both groups). The relatively high titers in newborns are corresponding to maternal IGg-antibodies. Conclusion: The different rate of infection in children and youth of two ethnic groups living in the same geographic region indicates the likelihood of intrafamilial contact instead of environmental factors as the source of infection. The relative low rate of infection of children as compared to young adults in both groups can be explained by a slow transmission from adults to children or a cohort effect due to improved living conditions.

\section{B:19 HIGH PREVALENCE OF HELICOBACTER PYLORI SPECIFIC IgG IN SERUM OF ALASKA NATIVES}

A.J. Parkinson, B.D. Gold, L. Bulkow, B. Khanna, R.B. Wainwright, K.M. Petersen. Arctic Investigations Program, National Center for Infectious Diseases, Centers for Disease Control \& Prevention, Anchorage

Helicobacter pylori is a common human infection world-wide, but its prevalence in Alaska Natives is not known. A total of 2080 serum specimens from Alaska Natives were randomly selected from banked sera and stratified by sex, age at the time of draw and community of residence. The sera had been collected between 1980 through 1986 and stored frozen at $-30^{\circ} \mathrm{C}$. Sera were tested for Helicobacter pylori-specific IgG using an enzyme immunosorbent assay developed at CDC. Overall, $76.5 \%$ of the samples were positive for Helicobacter pylori specific IgG, with similar rates by sex. Rates of positivity increased by age from $32.3 \%$ among $0-4$ year olds up to $76 \%$ in those 20 years or older. There was a marked regional variation in antibody prevalence, with $53.1 \%$ in South Central Alaska, to $84.4 \%$ in Interior Alaska. The regional variation was most pronounced among children of the youngest age group ( $0-4$ years), where rates ranged from 5\% in Anchorage to $65 \%$ in interior Alaska. This study demonstrates a high rate of past or current infection with Helicobacter pylori in the Alaska Native population. Prevalence rates of iron deficiency anemia, gastritis, gastric ulcer, anemia, and gastric carcinoma are high, in this population, consequently, treatment or prevention of this infection could have a significant impact on the overall health of the Alaska Native.

\section{B:20 HELICOBACTER PYLORI INFECTION IN DAY CARE CENTERS}

H.M. Malaty, J.E. Bouslyman, D.Y. Graham. VA Medical Center and Baylor College of Medicine, Houston, TX, USA

Objective: To investigate the current prevalence of $H p$ in children attending day care centers (DCC) and identify possible risk factors for infection. Methods: Children from 7 licensed DCC from different geographical locations in Houston participated (April 1995 to April 1996). Parents completed a questionnaire regarding demographics, household, duration and number of hours/day of attendance. Enrollment in 4 DCCs was based on the family's hardship economic condition. The 3 remaining DCCs charged fees for their service. $H p$ status was determined by ${ }^{13} \mathrm{C}$-UBT. Results: 101 healthy Black and white Hispanic children (47 boys and 54 girls), ages 2 to 5 were studied. $41(41 \%)$ had active $H p$ infection. There was no significant differences in $H p$ between Black and Hispanic children (43\% vs. $36 \%, \mathrm{p}=0.45$ ). The age distribution of $H$. pylori infection was relatively constant $(44 \%$ at $2,47 \%$ at $3,40 \%$ at 4 , and $32 \%$ at 5$) . H$. pylori infection was significantly more common in girls $(54 \%)$ than boys $(26 \%)$ $(P=0.004)$, and that difference remained after adjustments for the study variables. Independent risk factor for infection was DCC serving the low socioeconomic class $(\mathrm{OR}=2.9, \mathrm{CI}=1.1$ to 5.2$)$. There was no significant differences in $H p$ infection related to the child's household structure (i.e., number of children or adults live in the house, number of rooms, type of dwelling, or the duration of attendance at DCC). Conclusions: $\mathrm{Hp}$ infection is very prevalent in DCC serving lower socioeconomic families. DCC may also play a role in $H p$ transmission in children from middle and upper class families.

\section{B:21 WHAT IS THE MAGNITUE OF HELICOBACTER PYLORI INFECTION IN PATIENTS CONSULTING GASTROENTEROLOGISTS IN FRANCE?}

N. Broutet ${ }^{1}$, S. Tissot ${ }^{1}$, F. Cantet ${ }^{1}$, E. Tarral ${ }^{2}$, D. Lethuaire ${ }^{2}$, F. Mégraud '. ' Université Bordeaux 2, Bordeaux, France; ${ }^{2}$ Sanof-Winthrop, Gentilly, France

The prevalence of Helicobacter pylori infection in a population is usually determined for a given area and then extrapolated for the whole country. Furthermore, the magnitude of $H$. pylori infection in patients consulting gastroenterologists in the community is not known. In order to determine the prevalence and risk factors for $\boldsymbol{H}$. pylori infection, a randomized transversal study was conducted on patients consulting gastroenterologists for symptoms other than for the upper digestive tract in comparison to patients consulting for upper digestive tract symptoms (UDTS).

The sample included 2,249 patients of whom 1,044 were without UDTS (control group). This latter group was comprised of $53.3 \%$ men (mean age, $48.9 \mathrm{y}$ ) versus $43.6 \%$ in the UDTS group (mean age, $47.7 \mathrm{y}$ ). All patients filled out a questionnaire and their $H$. pylori status was determined by salivary specific IgG dosage (HP check EIA, Hoffmann La Roche) after collection with a special collection device, Orasure ${ }^{\otimes}(90 \%$ sensitivity, $97 \%$ specificity).

The prevalence of the infection was $24.7 \%$ in the control group versus $48.9 \%$ in patients with UDTS. A multivariate analysis was carried out and identified as risk factors for the infection: increase in age $(\mathrm{OR}=1.59$ [1.23-2.06]) and history of digestive tract problems $(O R=1.46[1.21-$ $1.75])$, while high education level $(\mathrm{OR}=0.46[0.33-0.64])$ and masculine gender $(\mathrm{OR}=0.62[0.51-0.74])$ were protective. The risk factors for UDTS were: history of digestive tract problems $(O R=1.46[1.21-1.75])$, and history of tobacco smoking regularly for more than six months $(\mathrm{OR}=1.23$ [1.02-1.49]) while feminine gender $(O R=0.81[0.67-0.98])$ was protected. No conclusions could be drawn for factors such as family history of gastric problems, geographic origin, eating habits, and previous treatments. This study shows that prevalence of $H$. pylori infection is currently as low as $25 \%$ in the adult population in France and that half of the patients consulting a gastroenterologist for UDTS are $H$. pylori positive.

\section{B:22 SEROPREVALENCE OF HELICOBACTER PYLORI IN A BIRTH COHORT OF 21-YEAR-OLD NEW ZEALANDERS}

\section{J. Fawcett, J. Shaw, M. Cockburn, M. Brook, G. Barbezat. University of} Otago, Dunedin, New Zealand

Objective: To determine the seroprevalence of Helicobacter pylori ( $H$. pylori) in a subset of a birth cohort of New Zealanders at age 21 and examine the association with risk factors and digestion-related symptoms.

Design: Assay of serum collected from members of a longitudinal study during 1993-94 and a survey of risk factors and digestion-related symptoms by interview and questionnaire.

Methods: Serum from 785 sample members (413 males, 372 females) of the 950 participating in the Dunedin Multidisciplinary Health and Development Study (DMHDS) at age 21 was analysed for $H$. pylori antibodies. Serum samples $(n=579)$ from the cohort at age 11 collected in 1983 were analysed for those who were seropositive at age 21 .

Results: The seroprevalence of $H$. pylori at age 21 was $4.1 \%$ (32/785), with proportionally more males in the seropositive group $\left(\chi^{2}=6.7, \mathrm{P}<\right.$ $0.01)$. Serum samples taken at age 11 were available for 19 of the seropositive group and $74 \%$ of these (11 males, 3 females) were seropositive. The seropositive group at age 21 was no different in the size of their families, but at age 5 contained proportionally more individuals from families of low socioeconomic status (SES) $\left(\chi^{2}=6.1, P<0.05\right)$. There was no difference between the two groups in terms of upper gastrointestinal tract symptoms, recent use of medications, smoking or alcohol consumption.

Conclusion: The seroprevalence of $H$. pylori among a birth cohort of 21-year-old New Zealanders is significantly lower than among most populations of about the same age in other countries. Seropositivity is higher in males and among families of lower SES, and is not associated with digestion-related symptoms. The seroconversion rate after age 11 appears to be low.

\section{B:23 ANTIGENIC CHARACTERIZATION OF HELICOBACTER PYLORI STRAINS FROM DIFFERENT PARTS OF THE WORLD}

J. Höök-Nikanne, G. Pérez-Pérez, M.J. Blaser. Vanderbilt University and Veterans Affairs Medical Center, Nashville, TN

Although Helicobacter pylori (Hp) have been considered to be relatively homogeneous at the phenotypic level, the important genotypic differences suggest the possibility of phenotypic variation. Our aim was to study antigenic differences of $\mathrm{Hp}$ isolates from developing and developed countries and the serum immune responses of people from a variety of populations. 
Methods: Bacterial strains from China, Thailand, Peru, Japan, Morocco, Zaire, and USA were studied. The bacteria were cultured on trypticase soy agar plates under microaerophilic conditions, bacterial whole cell lysates were prepared, protein concentrations standardized, and SDS-PAGE gels were performed and silver stained. Western blots using sera from Chinese, Japanese, Maori, Mexican, Thai and US (Caucasian and Pima Indian) patients, and from naturally infected monkeys were performed. In addition, rabbit immune sera against CagA, cytotoxin, whole-cell and heat shock protein antigens were used for analysis.

Results: Despite diverse origins, the strains showed conserved major bands of $60,56,31$ and $25 \mathrm{kDa}$. However, although differences in minor bands (including 100, 97, and $35 \mathrm{kDa}$ ) were detected, there was no obvious geographic pattern. The anti-CagA serum recognized 120-140 kDa bands in strains from around the world, and cagA genotype and phenotype correlated. Sera from Chinese and to a lesser extent from Japanese and Thai patients, in comparison with European, US, or Mexican patients, were more restricted in recognition of individual antigens. In contrast, monkey sera detected a wide variety of bands and identified numerous differences between strains. Those sera that especially recognized African strains also recognized specific antigens in Chinese and Japanese strains.

Conclusions: Conserved Hp antigens, such as CagA, exist and are recognized by sera from persons from many parts of the world. However, there is marked heterogeneity in $\mathrm{Hp}$ antigens expressed and in the serological responses of infected hosts, which is partially but not fully explained by geographic differences; such differences may be significant for serodiagnostic tests.

\section{B:24 AUSTRALIAN ABORIGINES DO HAVE HELICOBACTER PYLORI}

H.M. Mitchell ${ }^{1}$, A. Collins ' , G.R. Flannery ${ }^{2}{ }^{1}$ The University of New South Wales, Sydney, Australia; ${ }^{2}$ La Trobe University, Melbourne, Australia

Objective: Epidemiological studies indicate that ethnic groups of low socioeconomic status living in developed countries have a high prevalence of $H$. pylori infection, often comparable to that found in developing countries. An exception to this observation has been the reported finding of an extremely low prevalence of $H$. pylori infection (1.3\%) in Australian Aborigines (Dwyer et al 1988). This low prevalence is surprising given that the living conditions and socioeconomic status of this group are very similar to those found in the developing world. This discrepancy in relation to current epidemiological data led us to question the findings of this original study. One of us (GRF), involved in the collection of the Aboriginal sera, but not in the serological testing, was still in possession of these sera, therefore, given the improvements in serological testing since 1988, we re-examined a number of these sera using both ELISA and immunoblotting.

Methods: $\mathbf{5 0}$ of the original serum samples tested by Dwyer $e$ al were re-examined. These samples were randomly selected over all age groups (10-20 yrs-12 sera, 21-30 yrs-9 sera, 31-40 yrs-10 sera, 41-50 yrs-12 sera and $>50-7$ sera). IgG antibodies to $H$. pylori were measured using 2 ELISA assays and by Western blot.

Results: Of 50 serum samples examined, 17 (34\%) were found to have antibody levels diagnostic of $H$. pylori infection, $(25 \%$ of $10-20 \mathrm{yr}$ olds, $22 \%$ of $21-30 \mathrm{yr}$ olds, $50 \%$ of $31-40 \mathrm{yr}$ olds, $33 \%$ of $41-50 \mathrm{yr}$ olds and $43 \%$ of $>50 \mathrm{yr}$ olds). Seventeen sera (34\%) were found to be negative and $16(32 \%)$ to have intermediate results. Sera were classified as intermediate where several bands typical of $H$. pylori were found on the immunoblot but only 1 of the ELISA assays was positive.

Conclusions: Contrary to previous reports, this study indicates that Australian Aborigines living in remote areas of Australia do have a high prevalence of $H$. pylori infection, similar to that found in developing countries. In addition, the high percentage of intermediate results would suggest that this population may be infected with other closely related Helicobacter species. Further studies are required to pursue this issue.

\section{B:25 HIGH SEROCONVERSION FOR HELICOBACTER PYLORI (HP) IN ADULTS FROM A DEVELOPING COUNTRY}

A.M.R. Oliveira, D.M.M. Queiroz, G.A. Rocha, E.N. Mendes, S.B.I. Moura, A.L.T. Rabello. Lab. of Research in Bacteriology, UFMG and Instituto René Rachou, Belo Horizonte, Brazil

It has been demonstrated that in developed countries HP infection is rarely acquired in adult life with an annual seroconversion rate ranging from 0.3 to $0.5 \%$. However, there is no data on this subject in developing countries. Therefore, we studied, prospectively, between 1992 and 1995 , 219 volunteers adults ( 88 male, 131 female, mean age 35.9 yr., range 16 to $81 \mathrm{yr}$.) from a district of the metropolitan region of Belo Horizonte, Brazil. Before blood collection the patients responded to a questionnaire requesting information about sex, age, use of medication, water supply, sewage and monthly family income. Sera obtained in 1992 and in 1995 were stored at $-20^{\circ} \mathrm{C}$ until assayed. Anti-HP IgG antibodies were measured by ELISA using Cobas Core anti-HP EIA kit (Roche, Switzerland). A rise of $>100 \%$ above the cutoff was considered evidence of seroconversion. The population studied was of low socioeconomic level, $92.4 \%$ of the dwellings were supplied with treated city water and $88.3 \%$ were served by sewer network. Serum obtained from 173 patients in the first visit were positive for IgG HP antibodies (prevalence of infection: 78.9\%). During 32 months of follow-up 5 among 46 seronegative adults converted to seropositive with an annual infection rate of $4.0 \%$. One hundred and two of the 173 HP-positive sera obtained at the first visit were retested. Among them, 1 subject reverted to seronegative. The present study demonstrates for the first time, that in developing countries, differently from developed ones, HP infection is acquired in high rates throughout adult life. This finding may explain the high rates of reinfection observed in developing countries after HP eradication.

\section{B:26 INTESTINAL METAPLASIA SUBTYPES - A COMPARISON OF ETHNIC GROUPS IN NEW ZEALAND}

A.G. Fraser, S.-L. Peng, J.R. Jass. Departments of Pathology and Medicine, University of Auckland, New Zealand

Introduction: Gastric cancer is 2-4 times more common in Maori and $\mathrm{Pa}$ cific Is ethnic groups compared to European. This study aimed to determine if intestinal metaplasia (IM) was more common in these ethnic groups.

Methods: Patients attending for endoscopy for dyspepsia (aged from 30 to 75 yrs) had 2 biopsies taken from 3 areas; juxtapylorus, mid-antrum and body. The presence of $\mathrm{H}$. pylori (HP) was determined by at least two of the following tests - CLO-test, ${ }^{13} \mathrm{C}$ urea breath test, culture or histology. The presence, extent and subtypes of IM were assessed using H\&E, alcian blue, high iron diamine stains. Inflammation, activity and atrophy was graded (Sydney system). Scores for IM extent and histological variables were calculated.

Results: 158 patients; European 42\%, Maori 23\%, Pacific Is 35\%. HP and $\mathrm{IM}$ were detected in $88 \%$ and $60 \%$ of Maori/PI and $47 \%$ and $29 \%$ of Europeans. IM was detected juxtapylorus $34 \%$, antrum $28 \%$ and body $21 \%$. Type I IM detected in $43 \%$, type II $26 \%$ and Type III $7.0 \%$. Mean age of Maori/PI patients with IM and Type III IM was 53 and 51 yrs respectively compared to Europeans aged 65 and 72 years. $\mathrm{IM}$ was more extensive in Maori/PI patients. Univariate analysis showed that IM was associated with ethnicity ( $p=0.0001), \operatorname{HP}(p=0.001)$, chronicity score ( $p$ $=0.001)$, and atrophy score $(p=0.0001)$ but not age $(p=0.23)$, smoking $(p=0.225)$, endoscopic diagnosis $(p=0.09)$, gender $(p=0.97)$ or activity score $(p=0.26)$. The Odd's ratio (OR) of having IM for Maori and PI compared with European was $6.7(2.7,16.4)$ and $2.6(1.2,5.4)$ respectively. The OR of IM in HP-Pos patients compared to HP-Neg was 3.5 (1.6, 7.5).

Conclusion: HP and ethnicity are significant risk factors for IM and possibly gastric cancer. IM is more common, occurs at an earlier age and is more extensive in Maori and PI patients.

\section{B:27 PREVALENCE AND PREDISPOSING FACTORS OF PEPTIC} ULCER IN CIRRHOTIC PATIENTS

X. Calvet, M. Navarro, A. Lafon, M. Gil, I. Sanfeliu, E. Brullet, R. Campo, P. Mas, J. De Nadal. Consorci Hospitalari del Parc Tauli, Sabadell, Barcelona, Spain

Introduction: Peptic ulcer is frequently associated with liver cirrhosis. However, there are few data on factors predisposing to peptic ulcer in cirrhosis. In this sense, recent studies suggest that $H$. pylori plays no role on peptic ulcer development in cirrhosis. Objectives: 1 . To evaluate the point prevalence of peptic ulcer in cirrhosis patients. 2. To investigate the factors related to the development of peptic ulcer disease. Patients and methods: Two hundred and seven of 220 patients included in a study on the effect of dietary intervention in cirrhosis complications and survival accepted screening gastroscopy. Age, sex, educational level, liver cirrhosis etiology, Child-Pug score, ethanol and tobacco consumption, antecedents of peptic ulcer or ulcer surgery and presence of peptic ulcer at endoscopy were prospectively recorded. Sera were obtained at the beginning of the study, stored at $-70^{\circ} \mathrm{C}$ until analyzed and were tested for $H$. pylori antibodies using a commercial ELISA kit. Factors related to peptic ulcer were investigated using chi-square and Student-T test. Results: Point prevalence of peptic ulcer was $10.1 \%$ (5.8\% duodenal, $4.3 \%$ gastric). Only male sex (p 0.024 ) and seropositivity for $H$. pylori infection (p 0.03) were related with the presence of peptic ulcer at baseline endoscopy. Conclusions: Male sex and $H$. pylori are major factors predisposing to peptic ulcer in cirrhosis. 


\section{B:28 ASSESSMENT OF THE SENSITIVITY OF QPD32 IN HP POSITIVE DUODENAL ULCER PATIENTS TREATED WITH RANITIDINE BISMUTH CITRATE PLUS CLARITHROMYCIN}

A. Olivieri, F. Bamfi, G.F. De Carli, M. Mosconi, R. Tosatto, G. Recchia. Research and Development, Glaxo Wellcome S.p.A., Verona, Italy

QPD32 is the first specific questionnaire developed in Italy for measurement of Quality Life (QoL) of peptic ulcer and reflux oesophagitis patients. The aim of the present study was to evaluate the sensitivity (ability to measure changes in QoL induced by treatments) of QPD32 in $\mathrm{H}$. pylori (H.p.) positive duodenal ulcer patients undergoing an eradication therapy with ranitidine bismuth citrate (RBC) plus clarithromycin (CLA). Patients were enrolled into the study after duodenal ulcer had been diagnosed by endoscopy and H.p. detected by a positive CLO-Test and histology (both performed on one corpuz and one antral biopsy). All patients were treated with a 4 week course of RBC ( $400 \mathrm{mg}$ bd a day) plus CLA (250 mg qid) for the first 2 weeks. QPD32 was administered at baseline and at least 4 weeks after the end of the therapy.

Results: Ninety patients (64 males and 26 females; mean age 48 years) of the 200 planned, were enrolled into the study. Table 1 shows the mean scores and Standard Deviation (SD) for each QPD32 dimension at baseline (81 patients evaluable) and after therapy (78 patients).

Table 1

\begin{tabular}{lllrl}
\hline Dimension & Pain & Physical & Symptoms & Total QPD32 \\
\hline Baseline & $20.7 \pm 4.3$ & $17.6 \pm 2.9$ & $6.2 \pm 3.3$ & $61.1 \pm 10.9$ \\
After therapy & $24.5 \pm 3.6$ & $20.5 \pm 3.2$ & $19.8 \pm 2.9$ & $72.7 \pm 10.0$ \\
\hline
\end{tabular}

In each dimension and in the total score a highly significant increase ( $\mathrm{p}$ $=0.001$, Student's test) was observed, reflecting an improvement in QoL after treatment with RBC plus CLA which was associated with the healing of duodenal ulcer and with the almost complete remission of ulcer pain.

Table 2 summarizes the mean and SD for each QPD32 dimension before treatment for patients stratified by severity of pain.

Table 2

\begin{tabular}{lcllll}
\hline Grading of pain & No. pts & Pain & Physical & Symptoms & Total QPD32 \\
\hline Absent & 4 & $24.1 \pm 2.8$ & $16.4 \pm 1.7$ & $18.7 \pm 2.8$ & $65.1 \pm 6.1$ \\
Mild & 21 & $22.0 \pm 3.5$ & $18.4 \pm 2.7$ & $17.3 \pm 2.9$ & $64.7 \pm 9.4$ \\
Moderate & 45 & $20.7 \pm 4.4$ & $17.8 \pm 3.0$ & $16.1 \pm 3.2$ & $61.1 \pm 11.0$ \\
Severe & 8 & $16.6 \pm 1.9$ & $15.6 \pm 1.7$ & $13.1 \pm 1.7$ & $50.8 \pm 4.4$ \\
\hline
\end{tabular}

The scores markedly decreased with increasing of severity of pain, showing a progressive impairment of QoL when moving from absence of pain to severe pain.

Conclusions: QPD32 showed a high validity and sensitivity in measuring QoL of duodenal ulcer patients.

\section{B:29 ORAL CAVITY AS PERMANENT RESERVOIR OF H. PYLORI (HP) AND POTENTIAL SOURCE OF GASTRIC REINFECTION}

J. Pytko, E. Karczewska, J. Majka, S.J. Konturek. Inst Physiol \& Dept Dent, Univ Sch Med, Krakow, Poland

Studies in developing countries showed that both dental plaques (DP) and dentures are important reservoir for $\mathrm{Hp}$, whereas studies in developed countries failed to confirm this findings. This study was designed to compare the incidence of $\mathrm{Hp}$ in mouth cavity and in the stomach of 10 healthy and 100 peptic ulcer (PU) patients $18-69$ yr old. ${ }^{14} \mathrm{C}$-oral urea breath test (UBT) (with ${ }^{14} \mathrm{C}$-urea dissolved in water and confined for $5 \mathrm{~min}$ only to the mouth cavity - without swallowing), CLO-test, Hp culture on special " $\mathrm{Hp}$ Agar" and PCR for Hp DNA in saliva, gingival pockets and DP were used to assess the presence of $\mathrm{Hp}$ in mouth cavity. In the stomach, ${ }^{14} \mathrm{C}$-gastric UTB $\left({ }^{14} \mathrm{C}\right.$-urea $1 \mu \mathrm{Ci}$ in capsule dissolved in the stomach), endoscopy with biopsy for CLO-test, histology and culture were used to identified the Hp infection. Ten healthy subjects without symptoms and in 100 symptomatic patients with gastric or duodenal PU were tested just before the start and 4 weeks after the termination of 2 wk triple therapy (omeprazole 20 $\mathrm{mg}$ bd, clarithromycin $500 \mathrm{mg}$ td and metronidazole $500 \mathrm{mg}$ bd) when endoscopically PU were healed. All 10 healthy subjects were found to be Hp-positive in the mouth cavity but only 7 in the stomach. All PU patients before the therapy were found to be Hp positive both in the mouth and in the stomach. After triple therapy, 86\% PU became Hp-negative in their stomach but only in $5 \%$ of them the Hp was not detected in the mouth by culture and PCR. We conclude that the mouth is permanent reservoir of $\mathrm{Hp}$ both in healthy subjects and in PU before and after successful eradication of $\mathrm{Hp}$ from the stomach which may be a source of gastric reinfection.
4B:30 CO-INFECTION WITH MULTIPLE STRAINS OF H. PYLORI IS UNCOMMON EVEN IN DEVELOPING COUNTRIES: EVIDENCE BY DNA FINGERPRINTING OF SINGLE COLONIES

S. Miehlke, S.M. Small, O. Gutierrez, R. Thomas, D.Y. Graham, M.F. Go. VA Medical Center and Baylor College of Medicine, Houston, TX, USA; University Hospital San Juan De Dios, Bogota, Colombia

Background: It has been suggested that simultaneous infection with multiple strains of $H p$ may occur. To determine whether individual patients harbor infection with mixed $H p$ populations, we examined DNA fingerprints of $\mathrm{Hp}$ isolates and single colonies obtained from different gastric sites of patients from Colombia, a country with a high prevalence of $\mathrm{Hp}$ infection and $\mathrm{Hp}$-associated gastrointestinal diseases, poor hygienic conditions, and frequent environmental exposure to multiple and potentially more virulent $H p$ strains.

Methods: $H p$ isolates were cultured from antrum, corpus, and cardia of patients with gastric carcinoma. From each isolate 6 single colonies were obtained. Genomic DNA extracted from each $H p$ isolate and from single colonies was used to generate DNA fingerprints by REP-PCR. The presence of the cagA gene was also determined by PCR.

Results: In two patients 17 of $18 \mathrm{Hp}$ single colony DNA fingerprints were identical to each other and to the DNA fingerprint of the corresponding parent isolate. The remaining single DNA fingerprint was highly similar to that of the other 17 single colonies and to the isolate. The expected PCR amplicon for cagA was identified in all single colonies.

Conclusions: Identical DNA fingerprints were generated by REP-PCR for the majority of $H p$ single colonies obtained from different anatomical gastric sites of individual patients. This finding supports the contention that $H p$-positive individuals are infected with a single $H p$ genotype.

\section{B:31 GENOTYPING OF THE VaCA GENE IN HELICOBACTER PYLORI STRAINS ISOLATED FROM ULCUS PATIENTS IN GERMANY}

S. Bereswill ${ }^{1}$, S. Strobel ${ }^{1}$, B. Steinbrückner ${ }^{\text {}}$, G. Härter ${ }^{1}$, P. Allgaier ${ }^{2}$, H. Schwacha ${ }^{2}$, J. Sontheimer ${ }^{3}$, M. Kist ${ }^{1} .{ }^{1}$ Abt. Mikrobiol. \& Hyg., ${ }^{2}$ Med. Klinik II, ${ }^{3}$ Abt. Chirurgie I, Universitätsklinikum Freiburg, Germany

Recently it was demonstrated, that for the vacA gene of $H$. pylori, different alleles exist, which can be separately detected by PCR. Three types of signal sequences $(\mathrm{s} 1 \mathrm{a}, \mathrm{s} 1 \mathrm{~b}, \mathrm{~s} 2)$ and two types of mid regions $(\mathrm{m} 1, \mathrm{~m} 2)$ were found in 59 strains of north american origin. The allelic types represented the combinations $\mathrm{s} 1 \mathrm{a} / \mathrm{m} 1, \mathrm{~s} 1 \mathrm{~b} / \mathrm{m} 1, \mathrm{~s} 1 \mathrm{a} / \mathrm{m} 2, \mathrm{~s} 1 \mathrm{~b} / \mathrm{m} 2, \mathrm{~s} 2 / \mathrm{m} 2$ whereas type $\mathrm{s} 2 / \mathrm{ml}$ was not detected. Further analysis revealed that type $\mathrm{s} 1 / \mathrm{m} 1$ was phenotypically associated with high cytotoxic activity, with the presence of the cagA gene, and with peptic ulcer disease (PUD).

We have done vacA typing of $H$. pylori strains isolated from patients with PUD and duodenal ulcer disease in Germany. It was the aim of this study to assess wether vacA alleles exist in european strains and wether there are similar relationships to clinical manifestations. Analysis of vacA subtypes and the detection of cagA was done by PCR. The strains analysed so far carried the vacA type s1 at high frequency ( $>98 \%$ ). In all s1 strains analysed the cagA gene was detected. The $\mathrm{m} 1$ and $\mathrm{m} 2 \mathrm{mid}$ part sequences of the gene were found to be statistically combined with the signal sequences. The $\mathrm{s} 2 / \mathrm{m} 1$ type was not found. The $\mathrm{s} 2 / \mathrm{m} 2$ type was rarely detected and in the only strain found so far the cagA signal was absent. The vacA mid region of several strains was not amplified, indicating that a third type of mid region might exist. Analysis of additional strains $(>100)$ from each, a patient group with PUD and a control group with gastritis, which were recently isolated, shall provide data that might indicate wether particular vacA subtypes are related to clinical manifestations, as it was demonstrated for the american strains.

\section{B:32 HELICOBACTER PYLORI IS DETECTED BY PCR AND HYBRIDIZATION IN WATER FROM SWEDEN}

K. Hultén, H. Enroth, T. Nyström, L. Engstrand. Depts. of Clin. Microbiol. and Cancerepidemiol., Uppsala, Sweden

Introduction During the last years there has been studies performed on the possible waterborne transmission of $H$. pylori which could explain a fecal-oral spread of this microorganism in the environment. The aim of this study was to determine if $H$. pylori is present in water from Sweden.

Materials and methods Water samples were collected during the summer months from all 25 counties in Sweden. Municipal tapwater, water from the last basin/outside the wastewater treatment plant and tapwater from household wells were collected from each location giving a total of 74 water samples. Water samples were centrifuged, pellets resuspended, immunomagnetic separation was performed and the bacteria were lysed. Two different PCR assays which detect the adhesin gene and the 16S rRNA gene 
(RT-PCR) of $H$. pylori followed by hybridization were performed. Culture, Gram stain and urease activity were performed on the same pellets.

Results A high number of water samples gave positive results by both PCR assays combined with hybridization: $38 \%$ of the household wells, $12 \%$ of the municipal tapwater and $12 \%$ of the wastewater showed existence of $H$. pylori DNA. An additional number of samples, $17 / 74(24 \%)$ gave positive results only by the adhesin PCR assay or hybridization. Only $3 / 24(12 \%)$ of the household wells gave strictly negative results. No $H$. pylori was detected by culture or Gram stain, but two samples presented urease activity. The adhesin gene PCR assay was 10 times more sensitive than RT-PCR. The specificity of the assays has been previously tested against 38 closely related bacterial species, showing no crossreactivity to these or to 4 Helicobacter species.

Discussion $H$. pylori seems to be a common pathogen in Swedish waters, especially in water from household wells, and its existence is remarkably high, as already shown in water from Peru. This observation gives interesting clues to the transmission pattern of this microorganism.

We believe that the results, based on two PCR assays and hybridization, show true positive water samples.

\section{B:33 VECTOR POTENTIAL OF HOUSEFLIES (MUSCA}

\section{DOMESTICA) FOR HELICOBACTER PYLORI}

P. Grübel ${ }^{1}$, J.S. Hoffman ${ }^{1}$, F.K. Chong ${ }^{2}$, N.A. Burstein ${ }^{2}$, B.R. Sheff ${ }^{3}$, C. Mepani ${ }^{3}$, D.R. Cave ${ }^{1}$. 'Division of Gastroenterology, ${ }^{2}$ Division of Pathology, ${ }^{3}$ Division of Microbiology, St. Elizabeth's Medical Center of Boston, Boston MA, USA

The mode of transmission of $H$. pylori is unknown. Since viable bacteria have been shown to be excreted in human feces from infected individuals, and houseflies habitually develop and feed on excrement, we hypothesized that flies take up and harbor $H$. pylori and, in turn may contaminate the human environment. This study examined the possible vector potential of houseflies (Musca domestica) for H. pylori. Methods: Caged houseflies were exposed to freshly grown $H$. pylori on blood agar plates. After a 6 hour feeding period, the plates were removed and replaced with sterile petri dishes containing a droplet of sterile Brucella broth. At regular intervals, samples of houseflies were removed for microbiological and histological analysis, and petri dishes were replaced with fresh sterile plates. The flies' bodies, dissected intestinal tracts as well as released excreta droplets on the petri dishes were cultured for $H$. pylori. The urease, catalase, oxidase reaction, as well as Gram stain were used to identify $H$. pylori. Results: In contrast to control flies, viable $H$. pylori could be isolated from bodies, gut and excreta of the $H$. pylori exposed flies for as long as 24 hours after the initial feeding period. Histological analysis revealed Helicobacter-like organisms in the gut lumen and attached to intestinal epithelial cells. Conclusion: Houseflies can harbor viable $H$. pylori in their intestinal tracts. They are also able to disseminate viable $H$. pylori in excreta. They may therefore represent a significant reservoir and vector in the transmission of $H$. pylori. Houseflies may play an important role in $H$. pylori transmission in developing countries, where sanitary and domestic facilities are poor. 